\title{
ENTRE O PROGRESSO E A INSALUBRIDADE: ADMNISTRAÇÃO, MELHORAMENTOS URBANOS E HIGIENE NA SÃO PAULO DO FINAL DO SÉCULO XIX
}

\author{
BETWEEN THE PROGRESS AND UNHEALTHINESS: ADMNISTRATION, \\ URBAN IMPROVEMENTS AND HYGIENE IN SÃO PAULO IN THE END OF \\ 19 CENTURY
}

v. 8, n. 2 [13]

mai/ago (2016)
Bianca Melzi D. Lucchesi bia_md@hotmail.com

Dossiê: Cidade e Natureza

\section{Resumo}

Devido a uma série de epidemias e situações urbanas que facilitavam o contágio entre a população da cidade de São Paulo, o final do século XIX e começo do XX foi um período de grande desgaste para a saúde pública paulistana. Este estudo pretende mostrar de que forma o poder público, especialistas engenheiros e a população habitante dos cortiços de São Paulo encararam o problema da insalubridade e viveram as modificações urbanas e administrativas que acompanharam este período. A expansão demográfica vivida por São Paulo no auge do café criou a necessidade de mudança não só em um ou dois aspectos da vida urbana. O novo andamento da cidade, agora muito mais populosa e com riscos endêmicos, requer um plano com infraestrutura urbana de água, esgoto, iluminação, pavimentação e outros serviços públicos.

\section{Palavras-chave}

São Paulo. Século XIX. Sanitarismo. Habitação.

\begin{abstract}
Due to a series of epidemics and urban situations that facilitated the spread between the population of São Paulo, the late nineteenth century and early twentieth was a great period for the São Paulo public health. This study aims to show how the government, engineers, experts and the local population of São Paulo beehives faced the problem of poor health and lived urban and administrative changes that accompanied this period. The population growth experienced by São Paulo in the coffee height created the need for change not only in one or two aspects of urban life. The new progress of the city, now much more crowded and endemic dangerous, requires a plan with urban infrastructure of water, sewage, lighting, paving and other public services.
\end{abstract}

Keywords

São Paulo. 190 century. Sanitarism. Housing. 


\section{Desenvolvimento do artigo}

Durante o século XIX, o combate aos ambientes insalubres da cidade de São Paulo é travado pelo poder público com o intuito de desvincular da metrópole a fama de uma cidade doente que perdeu parte de sua população para a varíola, a febre amarela e a tuberculose (CARPITÉRO, 1997). Ao longo do século, diferentes foram as estratégias práticas e também políticas em torno desta missão. Englobando esta evolução urbana e também sua pluralidade de atores, veremos como se desenrolaram os melhoramentos urbanos que intuíram sanear a capital.

Até o começo do século XIX, as obras de interesse público como pontes e estradas eram realizadas na cidade a partir da iniciativa dos próprios moradores, a Câmara Municipal apenas coordenava tais trabalhos. Somente na década de 1830 que os melhoramentos urbanos passam a ser estruturados e qualificados pelo governo e atribuídos legalmente às diferentes instâncias ${ }^{1}$ : assuntos referentes a edificações públicas (escolas, hospitais, cadeias), sistemas de infraestrutura (vias de passagem, água, iluminação), jardins, passeios públicos, saneamento e obras de grande porte em geral, ficariam sob responsabilidade do Governo Provincial; já as obras referentes à alinhamento, limpeza, arborização e iluminação de vias públicas, estariam a cargo da Câmara Municipal. Mas a falta de autonomia financeira do município colaborou para que estas obras fossem concentradas na capital, onde a ação do poder público provincial foi mais marcante ao longo do século XIX, principalmente com as obras decorrentes do crescimento da economia cafeeira, como as estradas de ferro.

Sanear a capital significava também atentar para a saúde de seus habitantes. Visando unificar os serviços sanitários, o Império cria em 1850 a Junta de Higiene Pública. No entanto, seus trabalhos surtiram efeito pouco satisfatório com relação às melhorias nas condições de saúde pública, primeiro porque o serviço centralizado encontrava dificuldades de agir de acordo com as especificidades do território, segundo porque a organização do serviço estava atrelada a uma sociedade escravista que pouco se preocupava com os problemas sanitários da força de trabalho (COSTA, 1985). Três décadas mais tarde, o fluxo populacional aumentara e o espaço urbano ainda era palco de atuação para moléstias transmissíveis. Com o objetivo de solucionar os problemas da insalubridade do espaço paulistano e assim revigorar a saúde da capital, é criada, em 1884, a Inspetoria de Higiene. Apesar da iniciativa, o primeiro diretor da Inspetoria já afirmava não ter recursos necessários para a execução das propostas, entre as quais se destacava a drenagem dos terrenos pantanosos das várzeas, com prioridade para os bairros mais populosos como Brás, Pari e Luz (RODRIGUES, 2010).

${ }^{1}$ As atribuições do serviço são feitas a partir do Regimento Interno das Câmaras Municipais (Lei Imperial de 1/10/1828) e da Emenda Constitucional de 1834 (Lei Imperial de 08/10/1834). 
O período republicano que se estabelece a partir do final do século XIX modificou, entre muitas outras coisas, a estrutura administrativa relativa à saúde e obras públicas e redefiniu as atribuições das províncias, conferindo-Ihes maior autonomia política e financeira, a fim de melhor organizar os serviços públicos da capital. Assim, o município passa a contar também com uma estrutura administrativa ligada ao setor de obras, com a criação, em 1892, da Intendência de Obras Municipais, que em 1899 passa a se chamar Diretoria de Obras Municipais. A partir daí a responsabilidade do governo municipal não está ligada somente aos trabalhos rotineiros de alinhamento e calçamento, mas aos aspectos mais abrangentes da cidade, possibilitando o surgimento de projetos urbanos (SIMÕES JÚNIOR, 1991).

A primeira lei aprovada pela Câmara após as reformulações contidas na Constituição de 1891, dizia respeito às funções executadas pela Câmara Municipal, entre as quais estava englobada a função de Intendente de Higiene e Saúde Pública, que tratava de alimentação, hospitais, asseio, lavanderias, limpeza, chafarizes, abastecimento de água e esgoto, jardins, imigração, alojamentos, cemitérios, matadouros, mercados e feiras e estava responsável por tudo o que interessava à higiene e salubridade ou pudesse afetar a saúde dos habitantes da cidade (CERASOLI, 2004). Em 11 de novembro de 1891 são criadas três Secretarias (Interior, Justiça e Agricultura, Comércio e Obras Públicas), em 23 de maio de 1892 é criada uma comissão para verificação das condições higiênicas das moradias populares e em 18 de julho do mesmo ano é criado o Serviço Sanitário do Estado. A nova organização confere maior autonomia aos Estados e Municípios e descentraliza o serviço que antes se fazia a nível Imperial.

Para execução dos projetos técnicos, a lei no 262 cria, em 1896, a Comissão de Melhoramentos da Cidade, que seria uma espécie de corpo técnico da já existente Intendência de Obras. A Comissão, chefiada por um engenheiro civil que dispunha de um ajudante da mesma qualificação e auxiliares por ele designados, tinha por objetivo elaborar planos técnicos para um "conjunto de obras ou edificações a executar, para retificações, melhoramentos, embelezamentos e tudo o que seja necessário para que a Cidade seja colocada em condições estéticas e confortáveis". Em seu trabalho, a referida comissão se propunha a realizar um levantamento das edificações existentes no espaço da cidade para então planejar os melhoramentos necessários de sua responsabilidade. O Dr José Mendes Gonçalves, vereador da cidade de São Paulo e autor do projeto da Comissão de Melhoramentos, acreditava que a ação dos projetos deveria ser antecipada por um planejamento prévio, daí a importância e urgência da comissão em atuar no território e a necessidade de ser encabeçada por especialistas da área construtiva, como são os engenheiros civis. Todos os aspectos relacionados à vida urbana configuravam área de atuação desta comissão - ruas, praças, parques, mercados, fontes, cemitérios, canais, pontes e demais obras ou retificações (CERASOLI, 2004).

Atuando no espaço urbano, as estratégias de obras e sanitarismo visavam também adequar a habitação popular e aprimorar a vigilância sobre os modos e usos da cidade. A 
atenção da municipalidade com os cortiços paulistanos, por exemplo, faz parte de um amplo plano de saneamento que envolve melhoramentos nas condições de diversos setores, como mercados, várzeas e até as "carroças de café" que circulavam no centro. Mas, não bastava sanear a cidade sem dar conta da insalubridade da habitação pobre. ${ }^{2}$ Ponto de partida e destino final diário de todo agente paulistano, a casa coloca-se em evidência num momento da história em que a expansão demográfica da cidade de São Paulo trouxe problemas médicos e sociais para os ocupantes da urbe. Uma das maneiras de garantir a obediência da população diante das normas e medidas de saúde, era através da vigilância exercida pela polícia sanitária, que atuava nos domicílios de localização propensa à disseminação de doenças e estava apta a decretar multas e interdições. A polícia sanitária adentrava as moradias populares estabelecendo medidas higiênicas que poderiam chegar a exigências de adequação e até demolição das unidades habitacionais. Estando autorizada a adentrar domicílios sem aviso prévio, estes colaboradores da ordem e da higiene objetivavam assegurar que o recinto em linhas de risco e seus moradores estivessem dentro dos padrões de salubridade.

As providências exigidas pela polícia sanitária deveriam ser cumpridas pelos moradores e variavam entre: proteger os depósitos de água, remover entulhos, latas, garrafas, promover a limpeza de pátios, telhas e calhas. Além disso, a polícia sanitária também estava incumbida de notificar os casos de moléstias transmissíveis nas habitações inspecionadas. Neste caso, era imposto aos indivíduos que se achavam doentes o isolamento em quarto específico da moradia, e todos os que tiveram contato com o enfermo deveriam ser submetidos à vistoria para atestar seu estado de saúde. Antes de deixar o domicílio, a polícia sanitária providenciava a desinfecção de todos os cômodos da casa (CERASOLI, 2004). As visitas promovidas por este serviço não eram amplamente aceitas pela população vigiada. O Correio Paulistano notifica a existência de "pessoas que consideram importunas taes visitas", por serem realizadas em momentos impróprios, por exemplo, quando os moradores "se acham à mesa de suas refeições"3. Esta insatisfação pode vir da ideia humilhante que se fazia dessas visitas. Primeiro porque se a casa estava sendo vistoriada, quer dizer que não era bem vista pelas autoridades sanitárias. Segundo porque, caso fosse encontrado algum indivíduo doente - com varíola, febre amarela ou tuberculose, por exemplo - seria imediatamente levado por um carro específico do serviço de saúde para o hospital de isolamento e os demais moradores da casa deveriam ficar do lado de fora enquanto era feito o trabalho de desinfecção do ambiente que abrigava a doença. No caso de não cumprimento deste procedimento de desinfecção, a família do enfermo representaria um perigo que, ainda sob o aspecto humilhante da situação, poderia tornar-se público para manter a população sadia afastada de tais "infratores" das regras de saúde pública, como consta no artigo a seguir publicado pelo Correio Paulistano:

2 Os vilões da saúde e da moral paulistana eram os cortiços: lugar de aglomeração, do pobre, da sujeira, do vício, da promiscuidade.

3 O Correio Paulistano, 08/10/1893. 
Informamos que mudou-se hontem para a ladeira de Tabatinguera n. 48, uma família que havia perdido um seu parente, victima de varíola na Moóca. Consta-nos mais que roupas, colchões e mais trastes dessa mesma família não foram ainda desinfectados, receando-se por isso que o mal se propague na vezinhança. As reclamações vão com vista à solitude da Inspetoria de hygiene. 4

Outro artigo publicado pelo mesmo jornal demonstra uma iniciativa de persuadir os moradores dos cortiços a bem receber as visitas sanitárias domiciliares. O autor do artigo é desconhecido, mas é fácil perceber que seu foco reside em mostrar as vantagens de ter em casa a visita dos inspetores da higiene. Interessante notar que o autor deste artigo coloca as visitas sanitárias como algo que atinge beneficamente tanto os donos das casas quanto seus locatários:

A atividade que a Inspetoria de Hygiene tem desenvolvido no que diz respeito ao
policiamento sanitário só merece elogios por parte de todos quanto se interessam pelo
bem estar da capital. Das visitas repetidamente feitas às habitações particulares
resultam vantagens para o inquilino, que muita vez reclama improficuamente do
proprietário medidas urgentes, que a autoridade sanitária obtem, e para o
proprietário, porquanto a autoridade sanitária exige do inquilino os preceitos de
hygiene, que redundam na boa conservação do prédio. É por tanto, dever de todos
facilitarem às autoridades sanitárias a visita requisitada, além de que deve haver certo
amor próprio, por parte dos que são rigorosos no asseio, em ter ocasião de mostrar o
interior de suas habitações.

O argumento utilizado no artigo para atingir a população demonstra ser o autor conhecedor dos conflitos urbanos que permeiam o problema da habitação. As tensões entre proprietários, locatários e sublocatários eram comuns nos debates envolvendo os cortiços e muitas vezes tornavam-se maneiras de driblar a fiscalização no sentido de assumir advertências e multas provenientes de um quintal sujo, uma construção mal feita ou um ponto de água estagnada neste tipo de habitação em que o coletivo e o incerto se fazem presentes também quando o assunto é responsabilidade.

A redução da ocorrência de doenças e a garantia do bem-estar do corpo social dependiam desta vigilância sobre a saúde e a doença e também de reformas que facilitassem a circulação de ar e de indivíduos pela cidade, como o alargamento de ruas e avenidas, a retirada de habitações coletivas do centro urbano, melhorias no sistema de iluminação a gás e a regularidade das fachadas residenciais (ROLNIK, 1997, p. 34). Às transformações do espaço se unem as reformas das instituições políticas, alterações econômicas de impacto e chegada intensa de estrangeiros como novas experiências urbanas que contribuíram para que São Paulo fosse vista como uma cidade promissora (CERASOLI, 2004). Construtores deste cenário, os planos de remodelação da cidade visavam conceder-Ihe um aspecto mais moderno, regular com os preceitos higiênicos e capazes de prever as demandas futuras.

4 O Correio Paulistano, 28/07/1891 - "A Varíola" - artigo sem autor definido.

5 O Correio Paulistano, 08/10/1893 - "Visitas Sanitárias" - artigo sem autor definido. 
De acordo com Claudio Hiro Arasawa, a transformação do espaço urbano paulistano em fins do século XIX faz da cidade um espaço de exploração econômica capitalista, caracterizado pela implantação de redes de serviços de utilidade pública, como transporte, iluminação e esgoto, e pelo surgimento da especulação imobiliária englobando terrenos, aluguéis e construção civil, enquanto atividade econômica de grande prestígio entre os investidores particulares e de companhias construtoras e fabris.

Sobre os objetivos e as relações de poder presentes nas transformações urbanas na cidade de São Paulo, Arasawa considera que as populações pobres e as obras de engenharia foram o fator mobilizado pelas camadas dominantes para

(...) domesticação das áreas que passavam a ser incorporadas pelo espaço urbano, representando, a seu modo particular, objetivação de trabalho humano (...) que seria apropriada na forma de lucros imobiliários, tanto pelos grandes proprietários pertencentes à elite econômica da cidade, quanto pelas grandes companhias dedicadas à exploração dos negócios urbanos paulistanos(...). (ARASAWA, 2008, p. 160)

A estratégia capitalista exercida pelos empresários industriais e imobiliários de fato mantinha o trabalhador atado ao local de trabalho, proporcionando lucro ao setor imobiliário e controle de produção ao setor industrial. Mas a mobilização não era fruto apenas da iniciativa das camadas dominantes que objetivavam o lucro. Vale aqui ressaltar que o espaço não era apenas imposto pela necessidade de disciplinar seus habitantes ao trabalho e enriquecer seus construtores materiais. A população também construía seu espaço ainda que a partir da moradia coletiva e insalubre dos cortiços paulistanos. Obras de iluminação, saneamento e reparos no passeio público eram sucessivamente reivindicados por esta população, de modo que estes populares conseguiam atuar e melhorar as condições de seu espaço, que em grande escala, se refletia na organização urbana e de melhoramentos sanitários e estéticos de toda a capital. Nas correspondências que chegavam à Intendência Municipal, é comum depararmonos com solicitações de adequação do espaço, como construção ou desobstrução de sarjetas e evidencias de cobrança no que se refere à limpeza pública. Os pedidos encaminhados eram passados ao fiscal da região de onde provinha a queixa para, depois de confirmado e relatado o problema, este pedido ser avaliado pelo Intendente, como traz o exemplo a seguir: em 04 de fevereiro de 1898, o Sr. Bráulio Gomes solicita à Intendência Municipal de Obras a desobstrução da sarjeta que passa em frente a sua casa, situada na Rua Santo Amaro. Ciente da reivindicação, a Intendência envia, quatro dias depois, um fiscal que, em cumprimento ao despacho, realizou vistoria na Rua Santo Amaro e verificou necessidade de desobstrução das sarjetas e de desentupir alguns buracos na rua. "Do exame a que se procedeu na Rua Santo Amaro verificou-se que as sarjetas acham-se obstruídas com terra, o que impossibilita o escoamento rápido das águas das chuvas." A justificativa sanitária posta no documento 
legitima a Intendência a realizar a obra da Rua Santo Amaro, estando já em 19 de fevereiro confirmada e orçada em mais de 34 mil réis. ${ }^{6}$

As transformações urbanas não atingem somente a superfície da cidade, seu subsolo também é modificado. Entendendo as habitações insalubres como foco eminente de transmissão de doenças, médicos e engenheiros trabalham no sentido de "canalizar a saúde" por meio de redes de água e esgoto. O Estado demonstrava-se comprometido com os trabalhos de saneamentos que, segundo Bernardino de Campos, Presidente da Província de São Paulo, já teriam transposto "a phase mais theorica de sua tarefa. Entrou de vez no caminho da execução, e extensa é a área dos trabalho materiaes feitos (...)." $\mathrm{E}$ ilustra sua afirmação descrevendo justamente as obras de canalização tão indispensáveis à salubridade paulistana:

Há construcções monumentaes (...), como o são as destinadas ao abastecimento de água, a rede de exgottos, a drenagem do sub-solo, (...) a nova canalização e reetificação dos rios Tamanduathey e Tietê, para impedir a extravasão das águas e consequente alagamento da parte baixa da cidade, causa periódica de intoxicações palustres; a drenagem superficial, o dissecamento de pântanos, o escoamento de águas estagnadas, a remoção de focos de infeç̧ão, o calçamento de ruas e (...) a canalização e cobertura do Anhangabaú e o seu revestimento de pedra. ${ }^{8}$

No entanto, essa "phase theorica" dos trabalhos de saneamento teria sido colocada em prática somente na capital, priorizada por sua importância econômica. O mesmo documento que exprime a eficácia dos planos de saneamento na cidade de São Paulo afirma que

Evidentemente não era possível, de golpe, realizar em todo o Estado as obras collossaes que o ideal de um regular saneamento impõe. Seriam escassos o tempo e os recursos pecuniários. (...) As outras cidades reclamam o abastecimento de agua e muitas necessitam também de exgottos. ${ }^{9}$

A regulamentação específica acerca das habitações nasceu a partir dos trabalhos da Comissão de exame e inspeção das habitações operárias e cortiços no distrito de Santa Ifigênia. Esta comissão, formada em 1893, visava garantir através do controle sobre o local de risco o saneamento do espaço urbano. Dessa forma, acabou tornando-se parâmetro para os trabalhos de avaliação e condenação das moradias coletivas que se seguiram após seu lançamento. Suas conclusões apontavam para as inadequações construtivas das habitações como falta de luz e ventilação, altura da parede, alinhamento, umidade e infiltração, situação de torneiras e latrinas e estado de limpeza -, de modo a caracterizar as formas de moradia que deveriam ser modificadas, ao mesmo tempo em que ditava um modelo higiênico de construção

\footnotetext{
${ }^{6}$ AHMWL. Fundo Intendência Municipal. Série Obras Públicas, Subsérie Serviços, 04/027/1898.

7 AESP. Acervo Microfilmado. Relatório da Província. São Paulo -1896. p.61

8 Ibidem.

9 Ibidem.
} 
habitacional capaz de barrar o modelo indesejável (CERASOLI, 2004). A Comissão expõe em seus escritos as medidas indicadas para a prevenção de doenças e regulamentação das habitações populares, não só para aquelas já existentes no distrito trabalhado, mas também para as construções em plano, principalmente as vilas operárias. Para atender aos preceitos higiênicos do morar, o solo que irá receber a habitação deve ser enxuto, a casa deve ser equipada com sistema de esgoto preferencialmente de circulação contínua e o abastecimento de água deve ser feito por canalização. Quanto ao prédio em si, os especialistas estipulam regras e tamanhos para sua construção a fim de evitar os dois maiores problemas da habitação operária: a sublocação e a superlotação, que tornam ar e higiene elementos rarefeitos no cotidiano dos moradores. A preocupação com amplitude e funções dentro da casa se vê no $8^{\circ}$ parágrafo referente ao modelo habitacional, prevendo que "cada habitação deverá ter pelo menos três cômodos e cada cômodo não poderá ter área menor de 7,5 metros quadrados de superfície." ${ }^{10}$ Nesse sentido o relatório propõe o saneamento da cidade de São Paulo a partir do "diagnóstico e a terapêutica indicada para a unidade urbana" (CERASOLI, 2004, p. 167), ou seja,

Não bastava, (...) tomar enfim todas as medidas para manter em nível elevado a hygiene de uma cidade que cresce rapidamente e cuja população triplica em dez anos, é preciso também cuidar da unidade urbana (...), não já da habitação privada, mas daquela onde se acumula a classe pobre $(\ldots) .{ }^{11}$

O início da vigência das novas instituições republicanas é marcado pela preocupação com a saúde física e também com o comportamento dos moradores de bairros populares, devido à exiguidade de sua habitação. Torna-se necessário adequar a habitação e aprimorar a vigilância sobre os modos e usos da cidade, daí a necessidade de adequar também a forma como os serviços de inspeção e promoção de hygiene e melhorias urbanas seriam administrados nas provincias.

Toda estratégia sanitarista não só tornava "saudável" o centro metropolitano como também "aformoseava a paisagem da cidade" (ANDRADE, 1992). São Paulo carregava um status promissor pelo qual deveria zelar e para isso, o espaço público paulistano foi reajustado por uma política urbanística que envolve saneamento, embelezamento e a absorção de novos costumes por parte dos habitantes da capital, principalmente aqueles que habitavam os núcleos encortiçados e frequentavam os espaços insalubres da cidade.

${ }^{10}$ Relatório da Commissão de exame e inspecção das habitações operárias e cortiços do distrito de Santa de Ephigenia, 1893. op. cit. Cap. VII Do typo de habitação e villas operárias a adaptar.

${ }_{11}$ Relatório da Commissão de exame e inspecção das habitações operárias e cortiços do distrito de Santa de Ephigenia. op. cit. Cap. I Das habitações operárias nesta capital, e do seu exame de inspecção. 


\section{Referências}

\section{Acervos consultados}

Arquivo Público do Estado de São Paulo (AESP)

Arquivo Histórico Municipal Washington Luís (AHMWL)

\section{Documentos impressos}

Relatório da Commissão de exame e inspecção das habitações operárias e cortiços do distrito de Santa de Ephigenia, 1893. In CORDEIRO, Simone Lucena (org). Os cortiços de Santa Ifigênia: sanitarismo e urbanização (1893). São Paulo: Imprensa Oficial do Estado de São Paulo / Arquivo Público do Estado de São Paulo, 2010.

Arquivo Público do Estado de São Paulo - Acervo Microfilmado. Série Relatório da Província. São Paulo.

- Imprensa Oficial do Estado de São Paulo.

- O Correio Paulistano

\section{Bibliografia}

ANDRADE, Carlos Roberto Monteiro. (1992). A peste e o plano: o urbanismo sanitarista do Engº Saturnino de Brito. Dissertação de Mestrado. São Paulo: FAU USP.

ARASAWA, Claudio Hiro. (2008). Engenharia e poder: construtores da nova ordem em São Paulo (1890-1940). São Paulo: Alameda.

BRESCIANI, Maria Stella. (2010). Sanitarismo e configuração do espaço urbano. In CORDEIRO, Simone Lucena (org). Os cortiços de Santa Ifigênia: sanitarismo e urbanização (1893). São Paulo: Imprensa Oficial do Estado de São Paulo / Arquivo Público do Estado de São Paulo.

. (2001). História e Historiografia das cidades, um percurso. In: Historiografia brasileira em perspectiva. Org: FREITAS, Marcos Cezar. São Paulo: Contexto.

CANO, Jefferson. (2009). A cidade dos cortiços - os trabalhadores e o poder públicoem São Paulo no final do século XIX. In Trabalhadores na cidade - cotidiano e cultura no Rio de Janeiro e em São Paulo, século XIX e XX. Org. Elciene Azevedo...[et al]. Campinas: Edidora Unicamp.

CERASOLI, Josianne Francia. (2004). Modernização no plural: obras públicas, tensões sociais e cidadania em São Paulo na passagem do século XIX para o XX. Campinas SP: (Doutorado em História). p. 53 e 54. 
CARPINTÉRO, Marisa Varanda. (1997). A construção de um sonho: os engenheiroarquitetos e a formulação da política habitacional no Brasil São Paulo - 1917/1940. Campinas: Unicamp.

COSTA, Nílson do Rosário. (1985). Lutas urbanas e controle sanitário: origens das políticas de saúde no Brasil. Vozes: Rio de Janeiro.

RODRIGUES, Jaime. (2010). Da "Chaga Oculta" aos dormitórios suburbanos: notas sobre higiene e habitação operária na São Paulo de fins do século XIX. In CORDEIRO, Simone Lucena (org). Os cortiços de Santa Ifigênia: sanitarismo e urbanização (1893). São Paulo: Imprensa Oficial do Estado de São Paulo / Arquivo Público do Estado de São Paulo.

SIMÕES JÚNIOR, José Geraldo. (1991). O setor de obras públicas e as origens do urbanismo na cidade de São Paulo. In: Espaço \& Debates, no 34, p. 71 à 73 